\title{
Marketing analysis of levocarnitine and glucosamine preparations
}

\author{
L. Davtian'1, A. Voronkina'2, O. Khomych'1, O. Toziuk², D. Voronkin ${ }^{3}$ \\ ${ }^{1}$ Department of Pharmaceutical Technology and Biopharmacy, Shupyk National Medical Academy of \\ Postgraduate Education, Kyiv, ${ }^{2}$ Department of Pharmacy, National Pirogov Memorial Medical University, \\ Vinnytsya, ${ }^{3}$ Pharmaceutical Corporation "Yuria-Pharm," Kiev, Ukraine
}

\begin{abstract}
Aim: For the problem of the struggle of the human body with extreme strains, it is advisable to use active pharmaceutical ingredients that would directly participate in the metabolism having an actoprotective effect without exhausting the body. Levocarnitine and glucosamine have such properties. In this work was studied the development of the pharmaceutical market of Ukraine and the definition of market needs for combined and monopreparations of levocarnitine and glucosamine. Materials and Methods: The analysis of the market from January 2015 to September 2017 showed a significant increase in the sales of glucosamine hydrochloride and levocarnitine products, both in natural and monetary equivalents. Thus, the analysis of the data proves that the anabolic and frigoprotective properties of glucosamine have not received enough attention. The statistical data suggest that there is a growing market demand for levocarnitine for oral administration. Results: The ratio of the sales of glucosamine hydrochloride for injections and for oral use began to change when one of the Ukrainian drug manufacturers came out on the market with generic glucosamine hydrochloride for oral use. The changes in the price of one dose of glucosamine hydrochloride for oral use are due to the growth of the market share occupied by Ukrainian producers in this segment too. Such a shift in sales toward Ukrainian drugs contributes to the overall increase in the availability of drugs. Conclusions: Analysis of Ukrainian market of the glucosamine and levocarnitine preparations showed uneven distribution of foreign and domestic manufacturers.
\end{abstract}

Key words: Glucosamine hydrochloride, levocarnitine, market analysis, monopreparations

\section{INTRODUCTION}

$\mathrm{T}$ The problem of the struggle of the human body with extreme strains that ever occur in the way of the person is still relevant nowadays. Meanwhile in Ukraine, ATC group A14B "nonsteroidal anabolic drugs for system use" contains only two registered international non-proprietary names of medicinal substances. ${ }^{[1,2]}$ Those drugs increase resistance to of a certain part of the body to strain when applied but may have side effects elsewhere. It is advisable to use active pharmaceutical ingredients that would directly participate in the metabolism and would have an actoprotective effect without exhausting the body and without significant side effects. ${ }^{[3]}$ Levocarnitine and glucosamine have such properties. Their combination can be used in traumatology to improve the working capacity of people with inflammatory diseases of the joints and also can be widely used in the production of functional foods for people with high physical and psychoemotional loads, particularly for athletes. ${ }^{[4-7]}$ Existing research on the use of levocarnitine demonstrates its effect on increased load tolerance, as well as anabolic, cardioprotective, and antianemic effects. ${ }^{[5,6,8]}$ According to various literary sources, levocarnitine is classified into the groups of actoprotectors, antihypoxants, or non-steroidal anabolic drugs. ${ }^{[5-8]}$ Glucosamine is widely used for the treatment of arthrosis and osteoarthritis, while recent studies demonstrate its anti-inflammatory, anabolic, and frigoprotective activity. [4,9] The purpose of this work was to study the development of the pharmaceutical market of Ukraine for preparations of levocarnitine and glucosamine, as well as the definition of market needs for combined and monopreparations with the indicated active pharmaceutical ingredients.

Address for correspondence:

Alyona Voronkina, Department of Pharmacy, National

Pirogov Memorial Medical University, Pirogov str., 56, Vinnytsya, Ukraine. Tel.: +38050-461-42-61.

E-mail: algol2808@gmail.com

Received: 05-05-2018

Revised: $28-10-2018$

Accepted: 22-11-2018 


\section{MATERIALS AND METHODS}

\section{Chemicals and Drugs}

Levocarnitine and glucosamine hydrochloride was purchasedfrom Sigma Chemical Co., from HiMedia Pvt., Ltd. All other chemicals and reagents were analytical grade.

\section{Data collection}

The materials for the study were the data of the State Register of Drugs of Ukraine (collected on October 1, 2017) ${ }^{[1]}$ regarding the registered medicinal products containing levocarnitine and glucosamine hydrochloride (data included the information about the name and composition of the medicinal products, pharmaceutical form, manufacturer, and applicant), as well as information on the database "Morion" and Proxima Research for 2015$2017^{[10]}$ on the volumes of the sales of monopreparations of levocarnitine and glucosamine hydrochloride of various forms of the production measured both in financial terms (in Ukrainian Hryvnia [UAH] and U.S. dollar [USD]) and total quantity (packs).

For the marketing analysis, the monthly dynamics of the sales of processed medicines, the dynamics of changes in the demand balance for preparations of various forms of release, the change in the average packing price, and the dose of drugs were analyzed.

\section{RESULTS}

According to the State Register of Drugs, 23 drugs containing carnitine have been registered in Ukraine, five of them are substances, and 18 are medicines. 14 drugs contain levocarnitine, two are combined medications, and 12 are monopreparations. Most of these drugs - 12 - belong to the ATC group A16AA01 "Amino acids and their derivatives." Nine are solutions for injections, five are drugs for oral use, four of which are solutions for oral administration, and one - tablets.

There are two brands of drugs for carnitine for injection and two solid combined drugs in Ukraine. No liquid drugs containing carnitine are produced in Ukraine.

According to the State Register of Drugs in Ukraine, 38 registration certificates for glucosamine preparations are valid. Of these, five are substances and four are in bulk drugs. Of the 29 glucosamine medicines available on the market, 10 are glucosamine monopreparations, of which five are in the form of powder for oral solution, three are solutions for injections, and one is in the form of tablets. Of the 19 combined drugs containing glucosamine, one is cream and the rest are solid dosage forms in the form of capsules (six drugs) and tablets (12 drugs). Most of the glucosamine containing combined drugs found on the market are combinations of glucosamine and chondroitin (12 medicines), or glucosamine, chondroitin, and nonsteroidal anti-inflammatory drugs (NSAIDs) (diclofenac or ibuprofen)(five medicines). All drugs containing glucosamine are classified by the State Register of Drugs to the ATC group M "Drugs affecting the musculoskeletal system." 20 of them are attributed to the ATC group M01 "anti-inflammatory and antirheumatic drugs," and nine drugs to the ATC group M09 "Other drugs affecting the musculoskeletal system."

Thus, the statistics of the State Register of Drugs proves that the anabolic and frigoprotective properties of glucosamine have not received enough attention, while manufacturers continue to introduce on the market glucosamine generic drugs and its new combinations with NSAIDs for the treatment of diseases of the musculoskeletal system.

\section{DISCUSSION}

The next stage of the investigation was the analysis of the market development dynamics for monopreparations of the glucosamine and levocarnitine using monetary and natural equivalents. ${ }^{[1,12]}$

Monthly sales volumes show that despite the continuing general tendency of the market of growing sales volumes in UAH and decreasing volumes- in packs and USD equivalents, sales of levocarnitine drugs increased significantly in 2015-2017 [Figures 1 and 2]. It should be noted that the greatest increase in the volume of pharmacy sales in packs for levocarnitine was observed during the past year (from September 2016 to September 2017) [Figure 1].

It is important to note that the growth in sales of levocarnitine, both in money and in packs, occurred mainly due to the general increase in sales of levocarnitine for oral administration. This is particularly evident in USD sales. This is evidenced by the gradual increase in the proportion of sales (in UAH, USD, and in packages) of levocarnitine for oral administration from $60 \%$ to $70 \%$ [Figure 3] and from $55 \%$ to $65 \%$ [Figure 4 ] in both natural and monetary terms, respectively.

The average cost of one pack of the levocarnitine drugs (UAH) in recent years has practically not changed and amounted to $205 \pm 11 \mathrm{UAH}(8.47 \pm 0.82 \mathrm{USD})$ for drugs for oral administration and $261 \pm 18 \mathrm{UAH}(10.78 \pm 1.42 \mathrm{USD})$ for solutions for injections. For the analyzed period, the total cost of one package of the levocarnitine preparations in USD fell by $26 \%$ : By $21 \%$ for oral solutions and $32 \%$ for drugs for injections, which is mainly due to significant currency exchange rate fluctuations during 2015 [Figure 5]. 


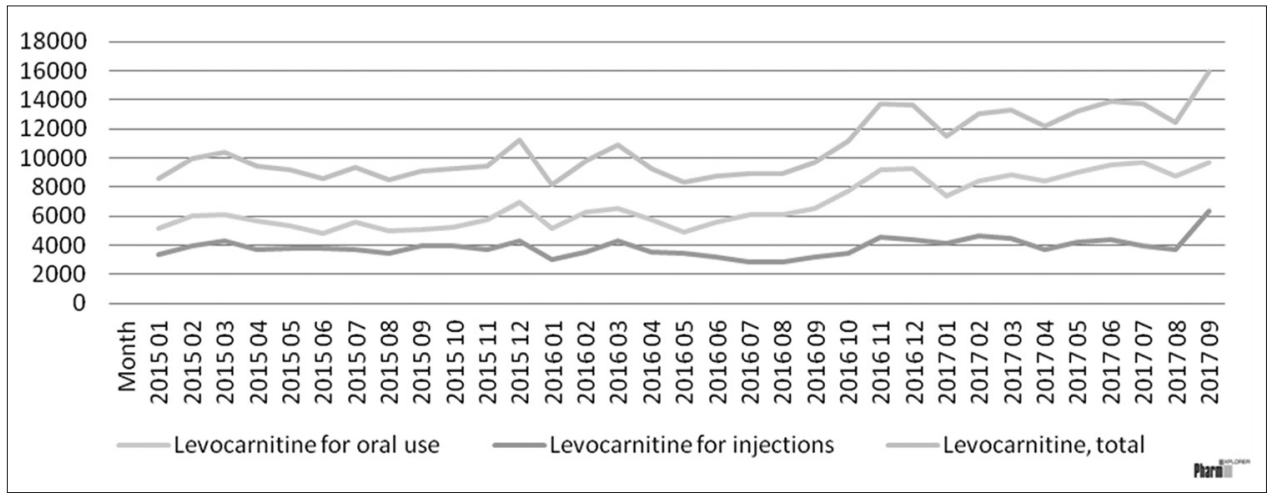

Figure 1: Dynamics of monopreparations of the levocarnitine sales, 2015-2017, packs

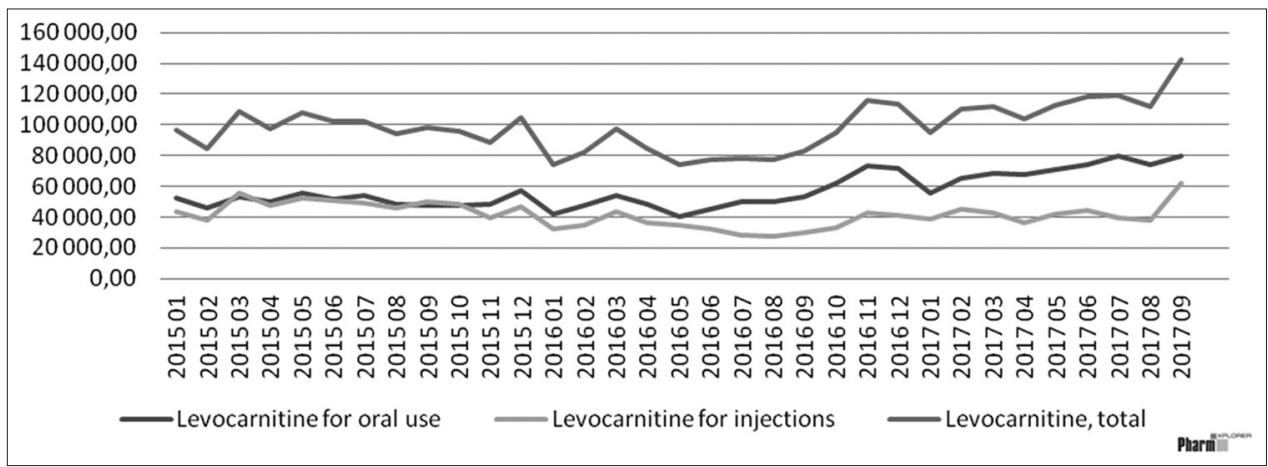

Figure 2: Dynamics of monopreparations of the levocarnitine sales, 2015-2017, USD

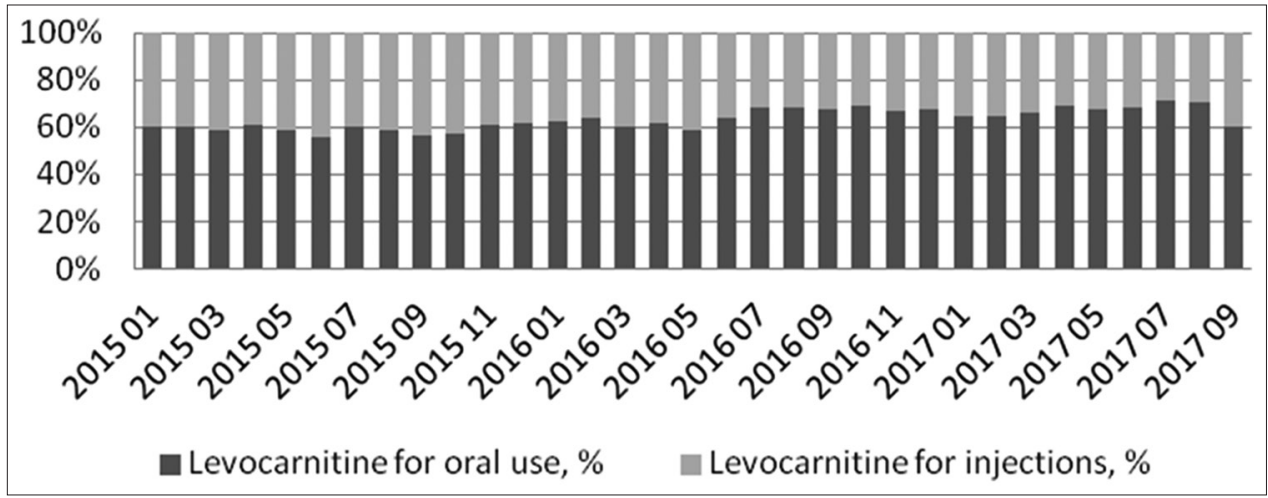

Figure 3: Dynamics of proportion of the share of sales (packs) for levocarnitine for oral use and for injections, \%

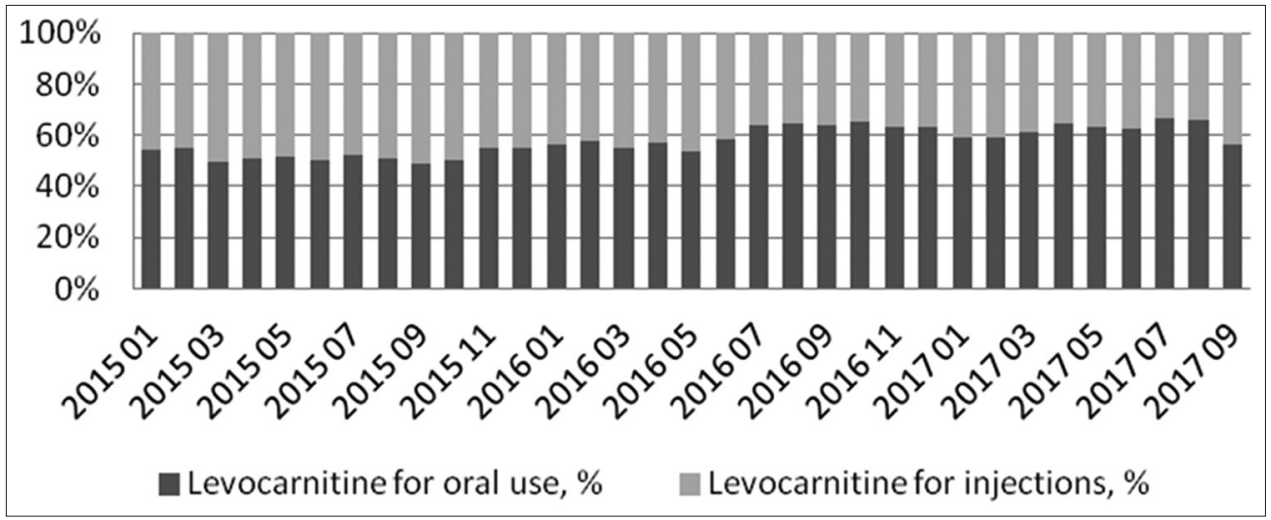

Figure 4: Dynamics of proportion of the share of sales (USD) for levocarnitine for oral use and for injections, \% 


\section{Consequently, the Statistical Data Suggest that there is a Growing Market Demand for Levocarnitine for Oral Administration ${ }^{[13,14]}$}

A similar analysis was carried out on the development of the market for glucosamine hydrochloride monoforms during 2015-2017 presented as a powder for oral solution preparation of $1.5 \mathrm{~g}$ glucosamine hydrochloride in a sachet of four manufacturers and glucosamine hydrochloride solution $200 \mathrm{mg} / \mathrm{ml}$ in $2 \mathrm{ml}$ ampoules of two manufacturers.

The analysis of the market from January 2015 to September 2017 showed a significant increase in the sales of glucosamine hydrochloride products, both in natural [Figure 6] and monetary terms: UAH and USD [Figure 7] equivalents. In the monetary equivalent, the main part of the increase was injections: Their sales increased 2.53 times in UAH (1.53 times in USD). Meanwhile, in natural terms (the number of packages), the highest growth-2.88 times showed preparations of glucosamine hydrochloride for oral administration, for which sales in money terms increased by 1.96 and 1.19 times in UAH and USD equivalents, respectively.

The ratio of the sales of glucosamine hydrochloride for injections and for oral use (packs) began to change in early

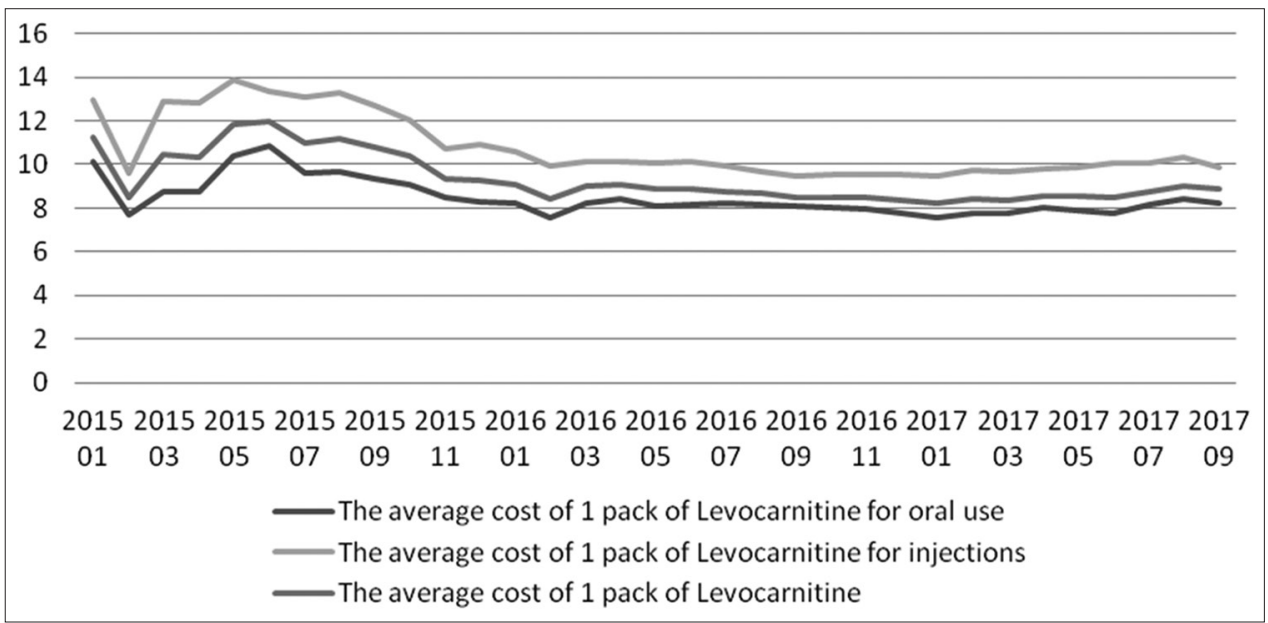

Figure 5: Dynamics of change of the average cost of 1 pack for levocarnitine for 2015-2017, USD

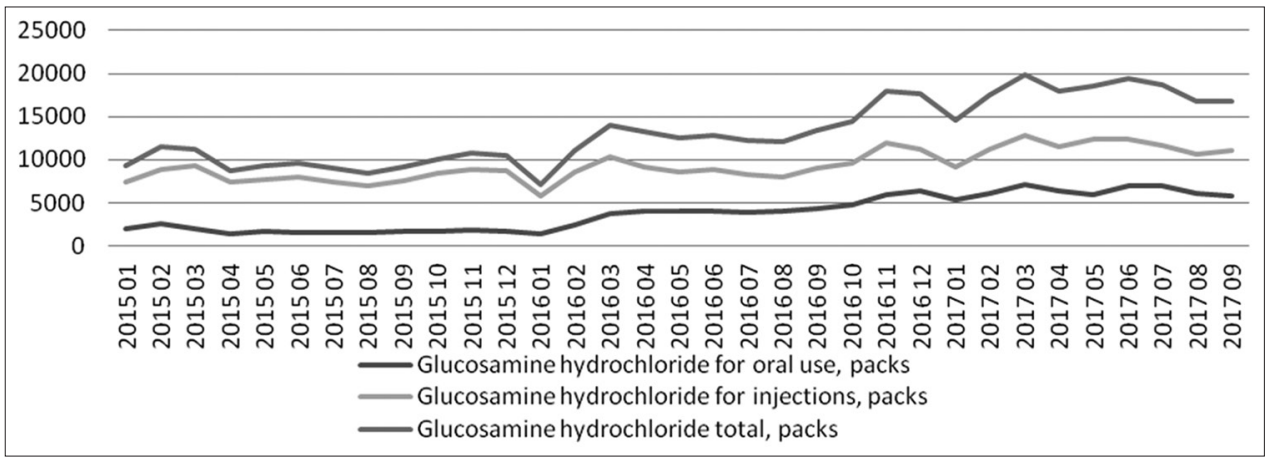

Figure 6: Dynamics of monopreparations of the glucosamine hydrochloride sales, 2015-2017, packs

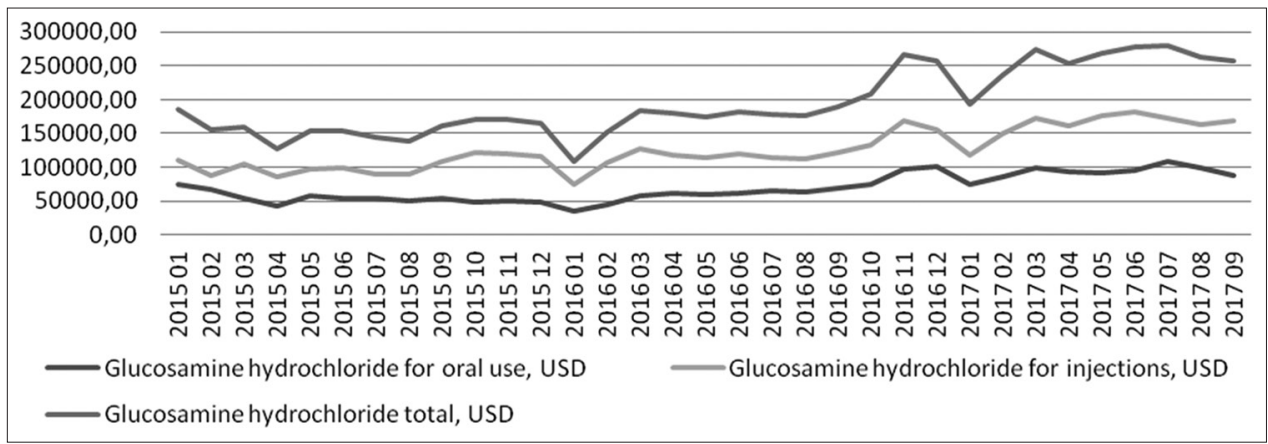

Figure 7: Dynamics of monopreparations of the glucosamine hydrochloride sales, 2015-2017, USD 
2016 when one of the leading Ukrainian drug manufacturers came out on the market with their product-generic glucosamine hydrochloride for oral use [Figure 8]. The overall dynamics of the gradual increase in the proportion of drugs for injections was interrupted, and by September 2017, the proportion of glucosamine hydrochloride preparations for oral administration increased from $21 \%$ to $35 \%$.

At the same time, in monetary terms, the proportion of medicinal products glucosamine hydrochloride in various forms during

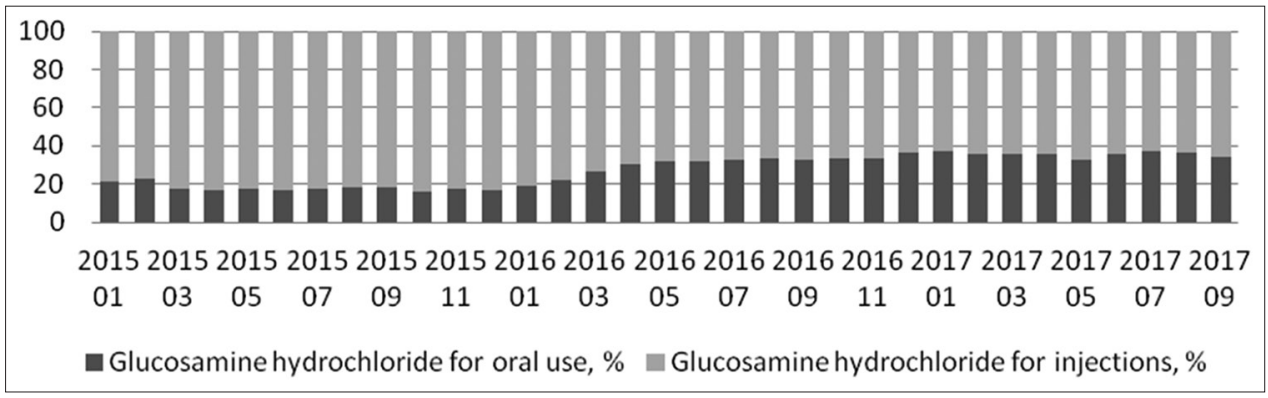

Figure 8: Dynamics of proportion of the share of sales (packs) for glucosamine hydrochloride for oral use and for injections, \%

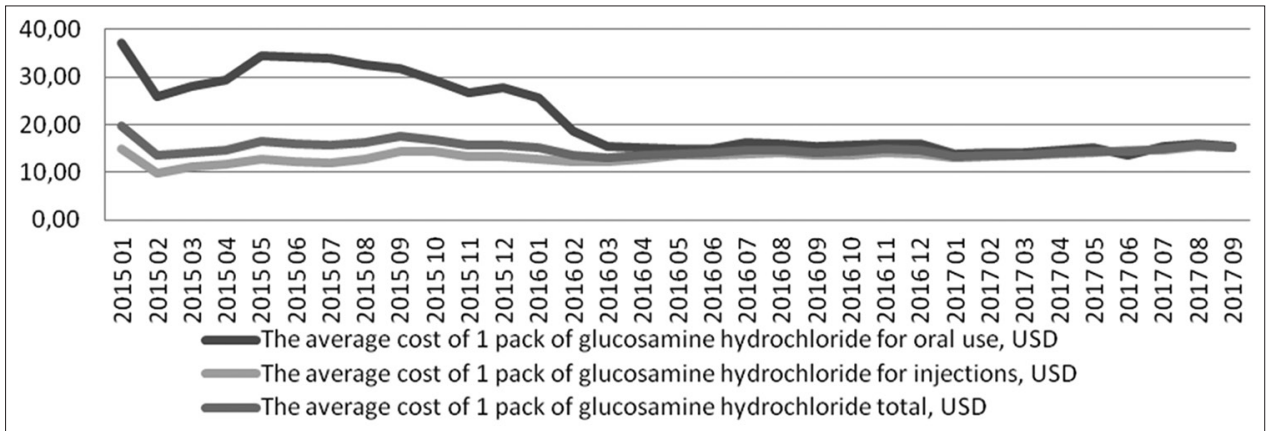

Figure 9: Dynamics of change of the average cost of 1 pack for glucosamine hydrochloride for 2015-2017, USD

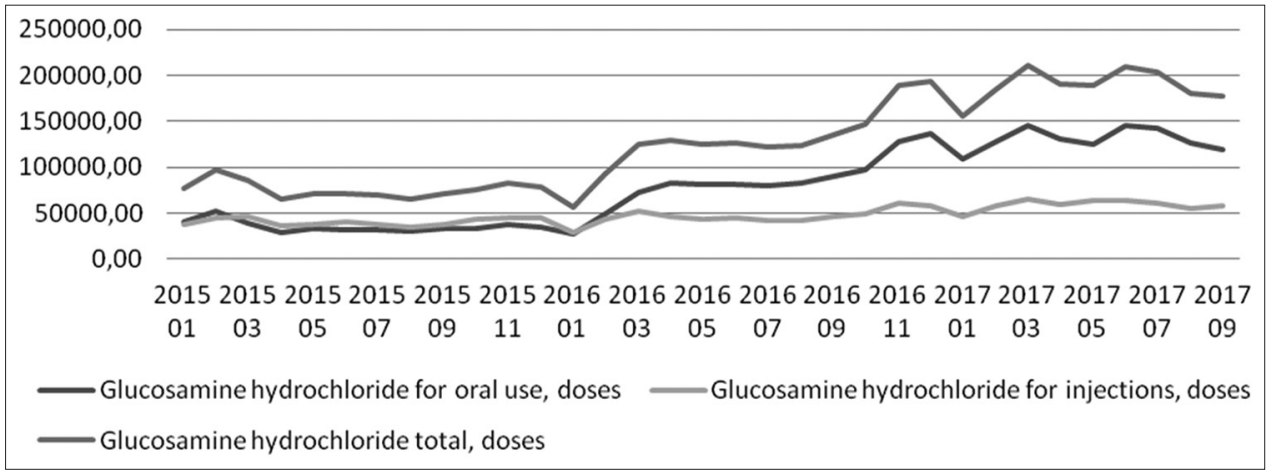

Figure 10: Dynamics of monopreparations of the glucosamine hydrochloride sales for 2015-2017, number of doses

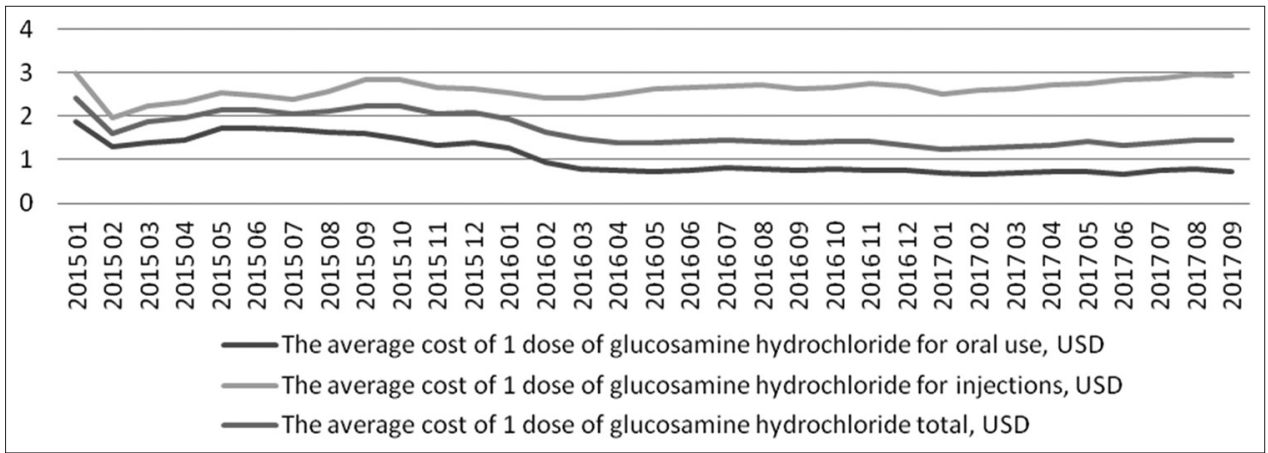

Figure 11: Dynamics of one dose price for monopreparations of glucosamine hydrochloride for 2015-2017, USD 


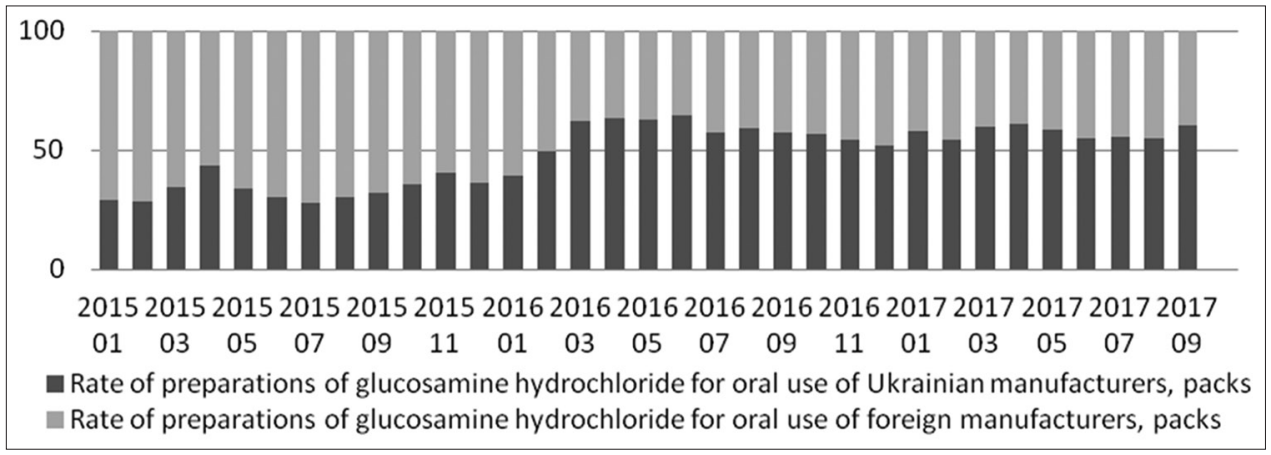

Figure 12: Dynamics of the rate of Ukrainian manufacturers on the market of monopreparations of glucosamine hydrochloride for oral use, 2015-2017 years, packs

this period did not change significantly, and after the exchange rate, fluctuations in early 2015 were about $65 \%$ for drugs for injections and $35 \%$ for drugs for oral administration.

This discrepancy of market shares in cash and in packs is mainly due to a significant change in the average price per pack of glucosamine hydrochloride for oral use [Figure 11], which for the analyzed period [Figure 10] decreased from 37.24 USD (588.91 UAH) to 15.36 USD (401.27 UAH).

The change in the average pack's price was due to the two factors: The decrease in the number of doses of the drugs in the package and the decrease in the cost of one dose of the drugs. Decrease in the average cost of a single dose of glucosamine for oral administration from 1.86 USD (29.44 UAH) to 0.74 USD (19.3 UAH) [Figure 9] contributed to the overall dynamics of demand growth for oral glucosamine hydrochloride preparations, which was reflected in the growth of the number of sold doses of the drugs for the analyzed period. For preparations for oral administration, the number of realized doses of the drugs increased almost 3 times. At the same time, the number of doses of the drugs for injection increased only 1.57 times and the average cost ranged slightly and was $2.62 \pm 0.21$ USD $(64.20 \pm 8.35 \mathrm{UAH})$.

The changes in the price of one dose of the glucosamine hydrochloride for oral use are due to the growth of the market share occupied by Ukrainian producers in this segment [Figure 12] from $25 \%$ in early 2015 to $60 \%$ at the end of 2017. Such a shift in sales toward drugs contributes to the overall increase in the availability of drugs: ${ }^{[15]}$ The cost of drugs is lower than similar imported drugs, in addition, the emergence of lower priced drugs at the market contributed to a decrease in the average price and on imported medicines. ${ }^{[16]}$

\section{CONCLUSIONS}

1. Analysis of Ukrainian market of the glucosamine and levocarnitine preparations showed uneven distribution of foreign and domestic manufacturers.
2. Monthly sales analysis in both physical and monetary equivalents showed an increase in demand for levocarnitine and glucosamine for oral administration in the period from 2015 to 2017; meanwhile, no drugs containing both medicinal matters were found on the market.

3. The anabolic and frigoprotective properties of glucosamine have not received enough attention, while manufacturers continue to introduce new combinations of glucosamine with NSAIDs for the treatment of diseases of the musculoskeletal system.

4. The analysis of the market demonstrated the overall positive impact of the market entry of Ukrainian manufacturers, which is manifested by a decrease in the average cost of packaging and dose of drugs, and increased availability of the medicines.

\section{REFERENCES}

1. Derzhavnyi Reiestr Likarskykh Zasobiv Ukrainy. Ministerstvo Okhorony Zdorovia Ukrainy: Departament Farmatsevtychnoi Diialnosti; 2017. Available from: http:// www.drlz.kiev.ua. [Last accessed on 2017 Zhov 01].

2. Kompendyum. Ukraina: Morion; 2017. Available from: $\mathrm{http}: / /$ www.compendium.com.ua. [Last accessed on 2017 Zhov 01].

3. Luk'ianchuk VD, Simonova IV. Aktoprotektory: Farmakolohiia ta farmakoterapiia. Farmakol Lik Toksykol 2015;2:14-26.

4. Bondariev Y, Shtryhol SI, Zupanets IA, Hrintsova OI. NatsionalnyiFarmatsevtychnyiUniversytet,Patentovlasnyk. Zastosuvannia Hliukozaminu Hidrokhlorydu yak Antyamnestychnoho ta Antyhipoksychnoho Zasobu. Patent Ukrainy; No. 61166; 2011.

5. Vertkyn AL. L-karnytyn $\mathrm{v}$ medytsynskoi praktyke: Dokazannie effekti. Cons Med 2012;1:3-6.

6. Kudoh Y, Aoyama S, Torii T, Chen Q, Nagahara D, Sakata H, etal. The effects of oral L-carnitine supplementation on physical capacity and lipid metabolism in chronic hemodialysis patients. Nephron Extr 2014;4:33-41.

7. Reuter SE, Evans AM. Carnitine and acylcarnitines. 
Pharmacokinetic, pharmacological and clinical aspects. Clin Pharmacokinet 2012;51:553-72.

8. Kudoh Y. L-Carnitine and cardiac function in chronic hemodialysis. J Urol Nephrol 2016;1:000102.

9. Bondarev EV, Shtrygol SY, Shtrygol YU, Shalamay AS. The frigoprotective effect of "Glucosamine C-BCPP" dietary supplement and the role of its components. Visnyk Farmatsii 2016;2:48-50.

10. Pharmxplorer. Proxima Research. 2012. Available from: http://www.pharmxplorer.com.ua. [Last accessed on 2017 Oct 01].

11. Nakamura M, Nagamine T. The effect of carnitine supplementation on hyperammonemia and carnitine deficiency treated with valproic acid in a psychiatric setting. Innov Clin Neurosci 2015;12:18-24.

12. Brown LM, Cupples N, Moore TA. Levocarnitine for valproate-induced hyperammonemia in the psychiatric setting: A case series and literature review. Ment Health Clin 2018;8:148-54.
13. Geier DA, Kern JK, Davis G, King PG, Adams JB, Young JL, et al. A prospective double-blind, randomized clinical trial of levocarnitine to treat autism spectrum disorders. Med Sci Monit 2011;17:PI15-23.

14. Tas S, Ozkan OF, Cikman O, Kiraz A, Akgun Y, Karaayvaz M. L-carnitine has a protective effect on the colonic mucosa during abdominopelvic radiotherapy in rats. Acta Cir Bras 2016;31:615-20.

15. Csete J, Kamarulzaman A, Kazatchkine M, Altice F, Balicki M, Buxton J, et al. Public health and international drug policy. Lancet 2016;387:1427-80.

16. Danzon PM, Mulcahy AW, Towse AK. Pharmaceutical pricing in emerging markets: Effects of income, competition, and procurement. Health Econ 2015;24:238-52.

Source of Support: Nil. Conflict of Interest: None declared. 